\title{
Quantification and correlation of Arbuscular mycorrhizae fungi spores and root colonization with the soil characteristics of Wheat (Triticum asativam L.) crop.
}

\author{
Tabassum Yaseen ${ }^{1 *}$, Fayaz Asad ${ }^{1}$, Muhammad Shakeel ${ }^{2}$, Aneesa \\ $\mathrm{Khan}^{1}$ and Ajmal Khan ${ }^{3,4}$ \\ 1. Department of Botany, Bacha Khan University Charsadda, KP-Pakistan \\ 2. Department of Biotechnology, Bacha Khan University Charsadda, KP-Pakistan \\ 3. Key Laboratory of Alpine Ecology and Biodiversity, Institute of Tibetan Plateau Research, \\ Chinese Academy of Sciences, Beijing 100101-China \\ 4. University of Chinese Academy of Sciences. No.19A Yuquan Road, Beijing, 100049-China \\ *Corresponding author's email: tabassumyaseen@bkuc.edu.pk \\ Citation \\ Tabassum Yaseen, Fayaz Asad, Muhammad Shakeel, Aneesa Khan and Ajmal Khan. Quantification and \\ correlation of Arbuscular mycorrhizae fungi spores and root colonization with the soil characteristics of Wheat \\ (Triticum asativam L.) crop. Pure and Applied Biology. Vol. 7, Issue 4, pp1268-1276. \\ http://dx.doi.org/10.19045/bspab.2018.700147
}

Received: 03/05/2018 Revised: 17/08/2018

Accepted: $31 / 08 / 2018$

Online First: 06/09/2018

\section{Abstract}

Microbiota are capable to interact with different types of trees, shrubs, and herbs thus play a key role in plants fertility productivity and sustainability. Arbuscular mycorrhizae fungi are beneficial microbiota which make the symbiotic association with plants. Previously, it was thought that symbiotic fungi facilitate plant growth. Thus, the current study was conducted to the comparative study between two stages of Triticum aestivum L., (fruiting and vegetative stage) of some farmland of District Charsadda. Our results indicated that Triticum aestivum L. form a mycorrhizal association in all fields, most significantly in the field of Behlola area, where the highest spore density was found due to the presence of high calcium and low magnesium. The most frequent species was found to be Glomus $(48.91 \%)$ followed by Sclerocystis $(28.42 \%)$ and Acaulospora $(22.68 \%)$ in the vegetative, and fruiting stage (i.e. $39.87 \%$, 33.21\%, 26.92\%) respectively. At vegetative stage Glomus, Sclerocystis, and Acaulospora revealed highest spore density of $53.38 \%, 34.51 \%$ and $25.00 \%$ in the fields of Tebana, Sarki and Behlola areas, respectively, and at fruiting stage high spore frequency such as $47.01 \%, 35.65 \%$, and $31.04 \%$ was observed in fields of Sarki, Ghazgi and Shah No. 6, respectively. The percent of root colonization showed the infection ranging from 20-100. Maximum infection was recorded for the fruiting stage followed by a vegetative stage of the plant.

Keywords: Acaulospora; Glomus; Microbiota; Sclerocystis; Triticum aestivum L.

\section{Introduction}

Arbuscular mycorrhiza is an association between plant roots and fungi, whereas fungi increase the nutrients uptake of the plants and get the food from plants partner [1]. In addition, these fungi have been 
reported to protect plants roots from various pathogens and confer tolerance against various abiotic stresses [2]. The association of plant roots with Arbuscular mycorrhizae (AM) fungi devise a strategy which enhances the nutrients uptake of the plant host, resulting the use of artificial fertilizers is reduced to a large extent [3]. AM fungi have been reported to play an important role in vegetation restoration, because of the extended network of hyphae, stabilize soil structure and maintain species diversity [4]. AM fungal association has been found to be useful under soil condition, where phosphorus is deficient, thus play a crucial role in terrestrial ecosystems due to establishing symbiotic interactions with plants [5]. They affect patterns of plant diversity in different ecosystems of the worldwide.

Previous studies indicated that functions of AM fungi are facilitated by biotic and abiotic factors exist around plant roots known as rhizosphere, microbial community, and ecosystems [6]. The density of spores, its distribution, and AM fungal composition have been observed to influence by environmental factors [7]. The root colonization percentage and spore population and its distribution varied by the seasonal fluctuations in temperature, moisture, and nutrients status such as nitrogen $(\mathrm{N})$, phosphorus $(\mathrm{P})$, potassium $(\mathrm{K})$, iron $(\mathrm{Fe})$ and Zinc $(\mathrm{Zn})$, etc. Similarly, low level of manganese (Mn), copper $(\mathrm{Cu})$, and $\mathrm{Zn}$ were more favorable for the fungal distribution and occurrence [8]. Whereas, increasing of $\mathrm{Fe}$ concentration in the soil promote the AM fungi spore diversity [9]. AM fungi is recognized for the extra valuable purpose and effect on associated plants viz., improve quality of soil, reduces leaching, cause stability, improve stress tolerance against abiotic (e.g. pH, drought stress and salt stress) and biotic factors (e.g. pathogens) [10].

Common bread wheat is an important cereal crop belonging to the grass family of Poaceae, formerly Gramineae and makes up the genus (Triticum spp.). It has been known to be one of the important cereal crops providing $37 \%$ of total calories to humans and $40 \%$ of the protein in our diet [11]. It was also found that wheat yield per unit area can be increased if we use high yielding wheat varieties, improved agriculture practices, genetically improved or modified wheat germplasm and improved agronomic practices [12]. Therefore, the present is study is conducted to find out the correlation of AM fungi spores and root colonization with the soil characteristics of wheat (Triticum asativam $\mathrm{L}$.).

\section{Materials and methods \\ Field sampling}

Five different sites (Sarki, Ghazgi, Behlola, Tebana and Shah No.6) were selected for the collection of roots and rhizospheric soil at District Charsadda. At each location, three farmlands (cultivated fields) were chosen. Roots and rhizosphere soil were dug out with a trowel at a depth of $0-15 \mathrm{~cm}$ after scraping away the top 1 $\mathrm{cm}$ layer of soil. From each field Root and rhizospheric soil samples of Wheat plants at two different stages (vegetative and fruiting) were collected randomly. Soil samples were packed in plastic bags for the extraction of spores and physicochemical parameters analysis.

\section{Spore extraction}

$100 \mathrm{mg}$ of each soil was passed through a fine sieve $(<2 \mathrm{~mm})$, in order to remove the dust and large particle and then soaked in $200 \mathrm{ml}$ of tap water for 24 hours. For each soil about three replicate were made in order to acquire the accurate result. The density of the spores was calculated using the standard procedure [13].

Relative Abundance (R.A) $=$ Number of spores of a genus $\times 100$

Total numbers of identified spores in a soil samples

\section{Root colonization}

To assess root colonization a previous method was followed [14]. The collected roots Wheat plant were cut into pieces with a section of around $1 \mathrm{~cm}$. The sections were 
washed to remove the soil particles and then boiled in $10 \% \mathrm{KOH}$ solution for ten minutes. Then the sections were washed with distilled water. For post clearance, v/v solution of distilled water with $\mathrm{NH}_{4} \mathrm{OH}$ $(0.5 \%)$ and $\mathrm{H}_{2} \mathrm{O}_{2}(0.5 \%)$ were used. After that, the sections were washed with distilled water and stained in $0.05 \% \mathrm{w} / \mathrm{v}$ methyl blue solution. The stained fragments were then put by slides and observed under the compound microscope in order to report the root infections type.

Percentage of root colonization = $\frac{\text { Number of VAM infected root }}{\text { Total number of root bits exmined }} \times 100$

\section{Results and discussion}

The present is to assess the correlation of AM fungi spores and root colonization with the soil characteristics of wheat (Triticum asativam L.) at the vegetative and fruiting stage. From both stages, three different types of spores were isolated from the selected locations which were Glomus, Sclerocystis, and Acaulospora. The highest spore density was found at Behlola followed by Shah No. 6, Sarki, and Tebana sites, whereas, the minimum spore density at the vegetative stage was recorded at Ghazgi site (Table $1 \& 2$ ). During the fruiting stage, the maximum spore density was recorded at Ghazgi followed by Shah No. 6, Tebana, Behlola and Sarki sites (Table 2). Root colonization, infection, and spores at different locations were different from each other (Table 3), could be due to nutrients availability and/or climatic change. The physicochemical analysis of the soil showed that $\mathrm{Ca}^{+}$(Calcium) content varied significantly in different sites (Table 4). At Behlola, it varied from 0.2$0.012 \%$ due to the large amount of $\mathrm{Ca}^{+}$ contents, which forms a higher mutualistic relation with mycorrhiza. This statement was in an agreement with previous findings where $\mathrm{Ca}^{+}$have been found play an important role in the biological system because it acts as a messenger in the cell functional process [15, 16]. The mutualistic and pathogenic plant microbes also depend on $\mathrm{Ca}^{+}$contents. In the current study, the Mg (Magnesium) contents were found to be in less amount in the same soil. Compared with previous studies, where higher mycorrhizal associations were observed at lower $\mathrm{Mg}$ contents [17, 18]. The present results Glomus was found to be the most dominant species followed by Sclerocystis and Acaulospora (Figure $1 \& 2$ ). Same density pattern of all the three spores were found previously [19]. At vegetative stage, the highest number of Glomus $(53.38 \%)$ was recorded in Tebana followed by Ghazgi (50\%), Behlola (48.17\%) and Shah No.6 (47.83\%) and Sarki $(45.77 \%$ ), respectively (Figure $3)$. whereas at fruiting stage, all the three types of spores recorded were $47.01 \%$ for Sarki, $41.21 \%$ for Ghazgi, $38.95 \%$ for Behlola, $37.60 \%$ for Tebana and $35.54 \%$ for Shah no.6 (Figure 4). The highest spore density for the Sclerocystis recorded was 34.51 and $33.65 \%$ in Sarki fields during fruiting and vegetative stage, respectively. Similarly, the highest number of spores of Acaulospora recorded was $25 \%$ in fields of Behlola and $31.04 \%$ for Shah No. 6 (Table. 1 \& 3). Yaseen et al. [2] also reported the mycorrhizal association during the vegetative and fruiting stage of Triticum aestivum. The frequency (\%) of overall spores during the vegetative stage observed for Glomus, Sclerocystis, and Acaulospora were 48.91, 28.42 and $22.68 \%$, whereas during fruiting stage it was recorded as $39.87 \%, 33.21 \%$, and $26.92 \%$, respectively. Our findings clearly highlighted the differences between both stages, which may be due to the usage of fertilizer with the passage of time. Generally, when farmers sow the seed they don't provide the fertilizer but when it reached to the fruiting stage they use fertilizer due to which the amount of spore density affected.

\section{Root colonization}

The root was also investigated for the infection of fungal species. Root colonization showed the infection ranging from 20-100 (Figure 5) Maximum 
infection was recorded for the fruiting stage followed by a vegetative stage of the plant. This may be due to the maturation of the plant roots as when plants reach to full maturity, they need more nutrients for the yielding, consequently forms maximum root colonization for the uptake of the highest number of nutrients. The maximum root colonization at fruiting stage was found for the Tebana followed by Ghazgi, Sarki, and shah no 6 . Whereas during the vegetative stage maximum infection was recorded for Behlola and Shah No. 6.

Table 1. Spore density during the vegetative stage of Triticum aestivum $\mathbf{L}$. Each value is the grand mean and standard deviation of three replicates from each location

\begin{tabular}{|c|c|c|c|c|}
\hline Locations & Glomus & Sclerocystis & Acaulospora & Total number of all spores \\
\hline Ghazgi & $22.00 \pm 1.73$ & $11.33 \pm 1.15$ & $10.67 \pm 0.58$ & 132 \\
\hline Saki & $21.67 \pm 1.15$ & $16.33 \pm 1.53$ & $09.33 \pm 1.53$ & 142 \\
\hline Tebana & $23.67 \pm 0.58$ & $11.67 \pm 0.58$ & $09.00 \pm 1.73$ & 133 \\
\hline Behlola & $26.33 \pm 0.58$ & $14.67 \pm 1.53$ & $13.67 \pm 0.58$ & 164 \\
\hline Shah No. 6 & $25.67 \pm 1.53$ & $15.33 \pm 0.58$ & $12.67 \pm 1.53$ & 161 \\
\hline
\end{tabular}

Table 2. Spore density during the fruiting stage of Triticum aestivum $\mathbf{L}$.

\begin{tabular}{|c|c|c|c|c|}
\hline Locations & Glomus & Sclerocystis & Acaulospora & Total number of all spores \\
\hline Ghazgi & $108.67 \pm 1.53$ & $94.00 \pm 1.00$ & $61.00 \pm 2.00$ & 791 \\
\hline Saki & $99.67 \pm 1.53$ & $71.33 \pm 1.53$ & $41.00 \pm 1.00$ & 636 \\
\hline Tebana & $94.00 \pm 2.00$ & $79.67 \pm 2.52$ & $76.33 \pm 1.53$ & 750 \\
\hline Behlola & $89.33 \pm 2.08$ & $71.67 \pm 1.53$ & $68.33 \pm 2.08$ & 688 \\
\hline Shah No. 6 & $89.67 \pm 2.52$ & $84.33 \pm 2.08$ & $78.33 \pm 1.15$ & 757 \\
\hline
\end{tabular}

Each value is the grand mean and standard deviation of three replicates from each location

Table 3. Root colonization of different locations of District Charsadda at host growth stage (vegetative and fruiting) of Wheat plant (Triticum aestivum L.)

\begin{tabular}{|c|c|c|c|}
\hline \multirow{2}{*}{ Sites } & \multicolumn{2}{|c|}{ Root infection (RC) } & --- \% ------" \\
\hline & & 2015 & 2016 \\
\hline \multirow{4}{*}{ Ghazgai } & Replicates & Vegetative Stage & Fruiting Stage \\
\hline & 1 & + & ++++ \\
\hline & 2 & ++ & +++ \\
\hline & 3 & + & +++ \\
\hline \multirow{3}{*}{ Sarki } & 4 & ++ & ++ \\
\hline & 5 & + & ++++ \\
\hline & 6 & ++ & +++ \\
\hline \multirow{3}{*}{ Tebana } & 7 & + & +++ \\
\hline & 8 & ++ & +++ \\
\hline & 9 & +++ & ++ \\
\hline \multirow{3}{*}{ Bahlola } & 10 & ++ & ++++ \\
\hline & 11 & + & ++ \\
\hline & 12 & ++ & +++ \\
\hline \multirow{3}{*}{ Shah No.6 } & 13 & +++ & +++ \\
\hline & 14 & ++ & ++ \\
\hline & 15 & +++ & ++++ \\
\hline
\end{tabular}

$+=$ Low infection, ++ = Medium infection, +++ = High infection, ++++ = Highest infection 
Pure Appl. Biol., 7(4): 1268-1276, December, 2018 http://dx.doi.org/10.19045/bspab.2018.700147

Table 4. Physio-chemical analysis of Triticum aestivum L. Rhizospheric soil samples

\begin{tabular}{|c|c|c|c|c|c|c|c|c|c|c|c|}
\hline \multirow{3}{*}{ Location } & \multirow{3}{*}{ Fields } & \multirow{2}{*}{\multicolumn{2}{|c|}{$\begin{array}{l}\text { Soil pH } \\
\ldots . . . \ldots . . \\
\end{array}$}} & \multirow{2}{*}{\multicolumn{2}{|c|}{$\begin{array}{c}\text { EC } \\
\text { dsm }^{-1} \\
\end{array}$}} & O.M & Lime & \multirow{2}{*}{ Sand } & \multirow{2}{*}{ Silt } & \multirow{2}{*}{ Clay } & \multirow{3}{*}{ Textural class } \\
\hline & & & & & & & & & & & \\
\hline & & $\mathbf{C a}$ & pH & Mg & EC & O.M & Lime & \multicolumn{3}{|c|}{-------- \% } & \\
\hline \multirow{3}{*}{ Ghazgai } & S1 & 0.05 & 6.10 & 0.01 & 0.38 & 1.45 & 8.50 & 53.20 & 28.14 & 18.66 & Sandy loam \\
\hline & $\mathbf{S 2}$ & 0.07 & 6.70 & 0.02 & 0.45 & 1.39 & 9.60 & 41.20 & 44.80 & 14.00 & Loam \\
\hline & S3 & 0.08 & 6.80 & 0.05 & 0.51 & 1.11 & 9.10 & 52.00 & 29.34 & 18.66 & Sandy loam \\
\hline \multirow{3}{*}{ Sarki } & S4 & 0.10 & 6.90 & 0.05 & 0.43 & 1.15 & 10.50 & 49.40 & 33.70 & 16.90 & Loam \\
\hline & S5 & 0.06 & 6.20 & 0.03 & 0.57 & 1.00 & 10.10 & 56.60 & 32.80 & 10.60 & Sandy loam \\
\hline & S6 & 0.08 & 6.30 & 0.04 & 0.58 & 1.06 & 8.60 & 47.70 & 37.70 & 14.60 & Loam \\
\hline \multirow{3}{*}{ Tebana } & S7 & 0.07 & 6.50 & 0.04 & 0.27 & 1.19 & 8.20 & 50.90 & 37.10 & 12.00 & Loam \\
\hline & S8 & 0.04 & 5.80 & 0.009 & 0.34 & 1.15 & 8.20 & 44.00 & 43.44 & 12.66 & Loam \\
\hline & S9 & 0.010 & 5.00 & 0.005 & 0.33 & 1.52 & 10.10 & 10.60 & 41.40 & 48.00 & Clay Loam \\
\hline \multirow{3}{*}{ Bahlola } & S10 & 0.012 & 6.70 & 0.003 & 0.31 & 1.59 & 10.10 & 14.60 & 39.40 & 46.00 & Clay Loam \\
\hline & S11 & 0.20 & 5.10 & 0.006 & 0.23 & 1.55 & 10.50 & 18.66 & 28.34 & 53.00 & clay loam \\
\hline & S12 & 0.08 & 6.70 & 0.06 & 0.45 & 1.39 & 9.60 & 57.60 & 33.80 & 10.60 & Sandy loam \\
\hline \multirow{3}{*}{ Shah Number 6} & S13 & 0.04 & 6.20 & 0.001 & 0.61 & 1.10 & 7.10 & 45.00 & 31.12 & 18.66 & Sandy loam \\
\hline & S14 & 0.01 & 7.90 & 0.015 & 0.51 & 1.05 & 9.10 & 51.40 & 29.90 & 16.90 & Loam \\
\hline & S15 & 0.10 & 7.20 & 0.02 & 0.25 & 0.91 & 8.10 & 60.10 & 37.10 & 10.60 & Sandy loam \\
\hline
\end{tabular}


Yaseen et al.

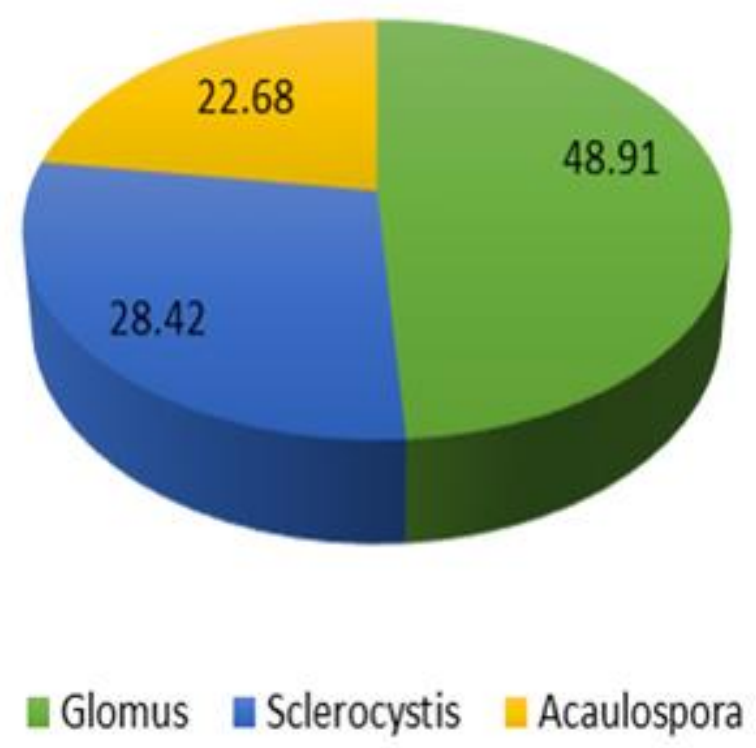

Figure 1. Combined percentages of the spores during the vegetative stage of Triticum aestivum $\mathrm{L}$.

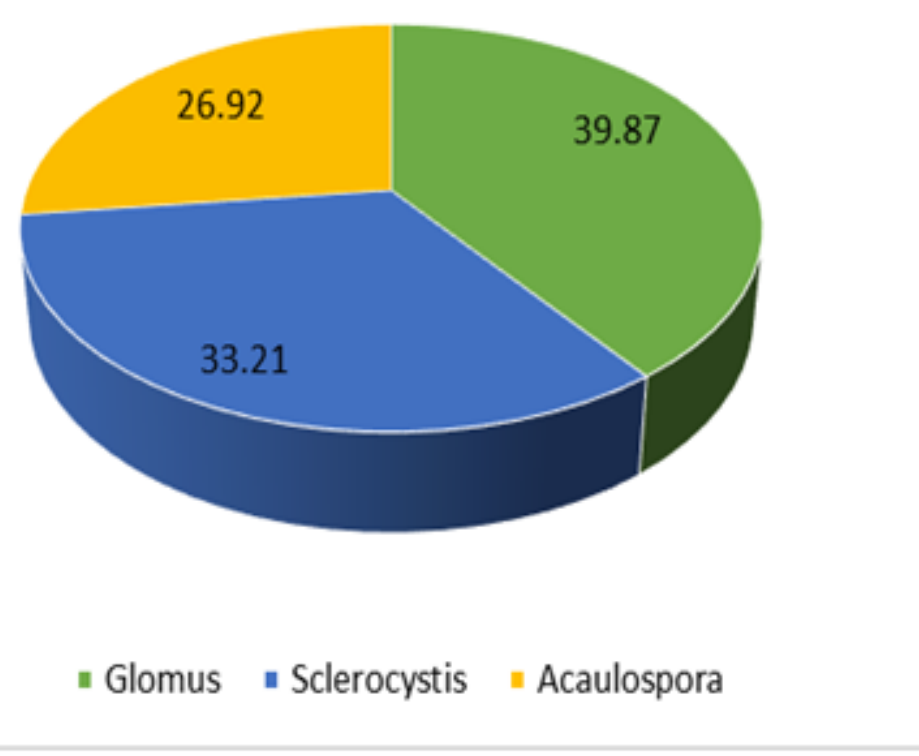

Figure 2. Combined percentages of the spores during the vegetative stage of Triticum aestivum $\mathrm{L}$. 


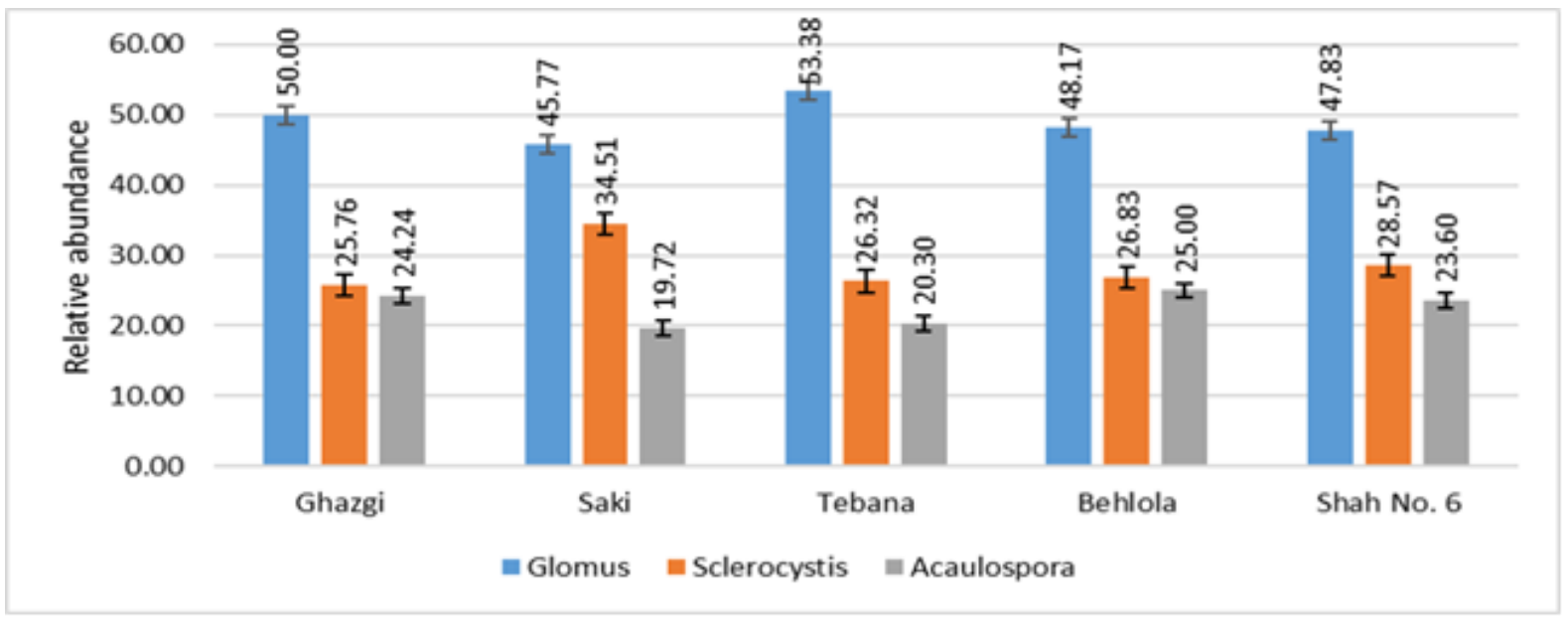

Figure 3. Relative abundance of the spores during the vegetative stage of Triticum aestivum $L$.

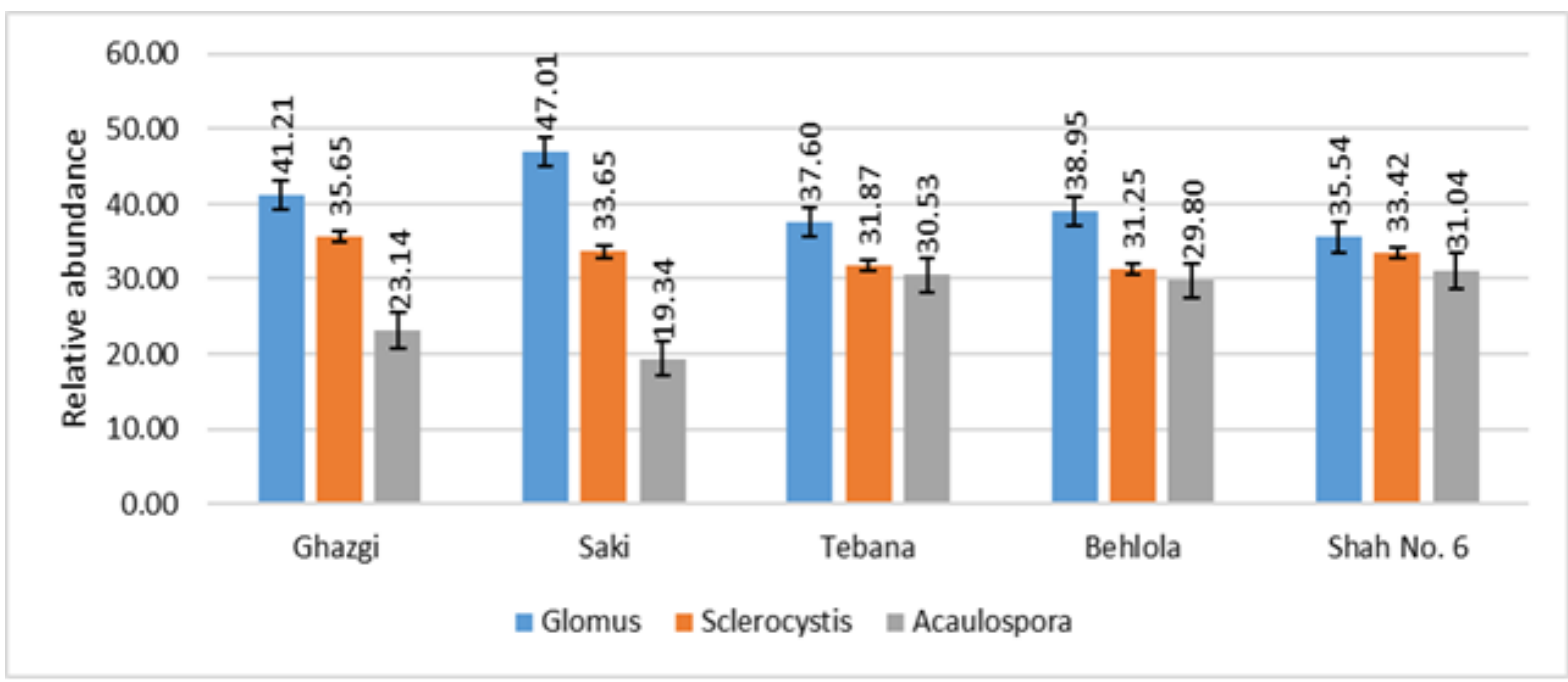

Figure 4. Relative abundance of the spores during fruiting stage of Triticum aestivum L.

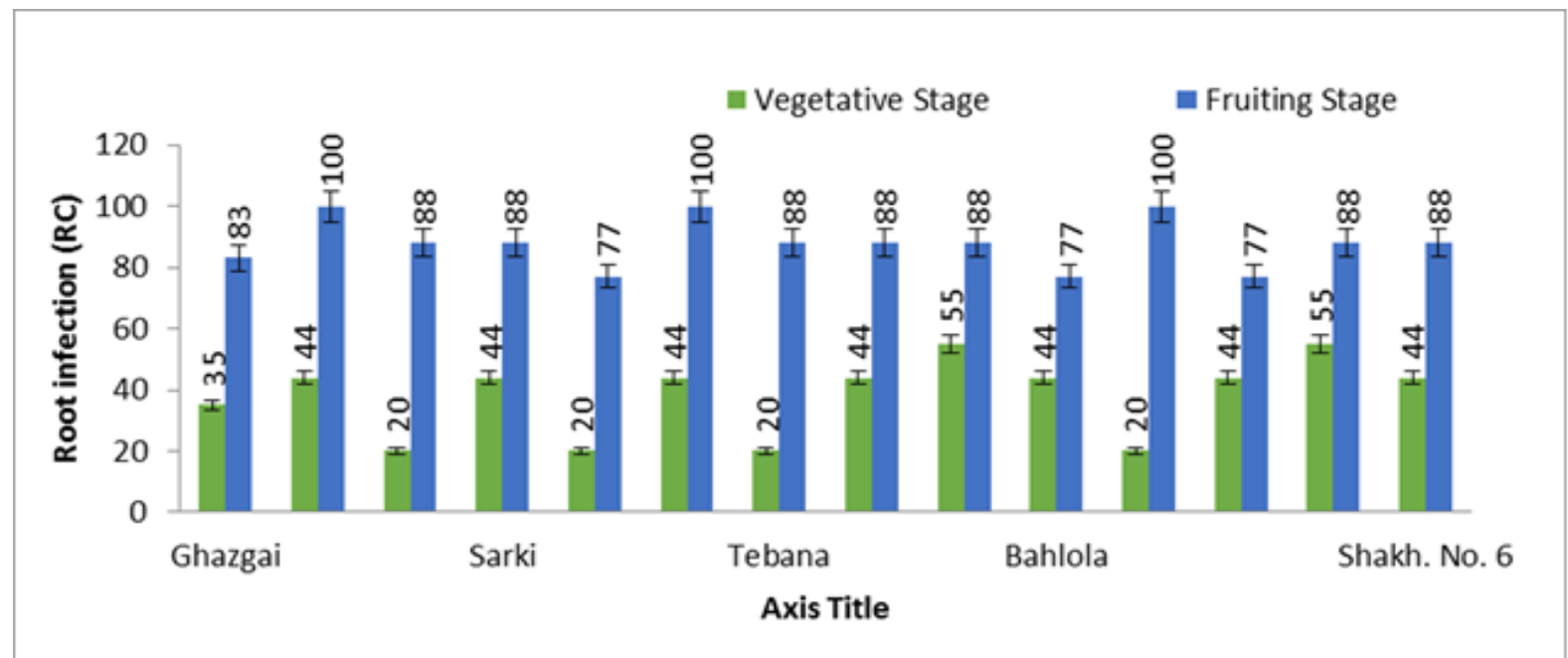

Figure 5. Root infection value in a different location at both the vegetative and fruiting stage of Triticum aestivum $\mathrm{L}$. 


\section{Conclusion}

The present study revealed that the mycorrhizal associations were closely linked with physicochemical parameters of the soil. The calcium contents help in the promotion of fungal mycorrhiza. The mycorrhizal association was found to be directly proportional to the calcium contents, whereas inversely proportional to the magnesium contents. Completely mature roots form more association with mycorrhiza instead of immature roots. The Glomus forms the highest community because of the highest number of species present in this genus. The mycorrhiza was dependent on the usage of fertilizers and environmental factor. High care is needed during the plantation of crops to use authentic fertilizers like NPK.

\section{Authors' contributions}

Conceived and designed the experiments: $\mathrm{T}$ Yassen, $\mathrm{F}$ Asad \& A Khan, Performed the experiments: $\mathrm{T}$ Yassen \& A Khan, Analyzed the data: T Yassen, A Khan \& A Khan, Contributed materials/ analysis/ tools: F Asad, M Shakeel \& A Khan, Wrote the paper: T Yassen \& F Asad.

\section{References}

1. Gerdemann J (1968). Vesiculararbuscular mycorrhiza and plant growth. Ann Rev of Phytopathol 6(1): 397-418.

2. Yaseen $T$, Shakeel $M$ \& Ullah $F$ (2017). Comparing the association of Arbuscular Mycorrhizal fungi with Wheat crop from District Mardan and Charsadda. Pak $J$ of Phytopathol 29(1): 79-88.

3. Almagrabi $\mathrm{O} \&$ Abdelmoneim $\mathrm{T}$ (2012). Using of Arbuscular mycorrhizal fungi to reduce the deficiency effect of phosphorous fertilization on maize plants (Zea mays L.). Life Sci J 9(4): 1648-1654.

4. Bothe H, Turnau K \& Regvar M (2010). The potential role of arbuscular mycorrhizal fungi in protecting endangered plants and habitats. Mycorrhiza 20(7): 445-457.
5. Smith SE, Jakobsen I, Grønlund M, \& Smith FA (2011). Roles of arbuscular mycorrhizas in plant phosphorus nutrition: interactions between pathways of phosphorus uptake in arbuscular mycorrhizal roots have important implications for understanding and manipulating plant phosphorus acquisition. Plant Physiol 156(3): 1050-1057.

6. Soka G \& Ritchie M (2014). Arbuscular mycorrhizal symbiosis and ecosystem processes: prospects for future research in tropical soils. Open $J$ of Ecology 4(1): 11.

7. Mohammad MJ, Hamad SR \& Malkawi HI (2003). Population of arbuscular mycorrhizal fungi in semiarid environment of Jordan as influenced by biotic and abiotic factors. J of Arid Environ 53(3): 409417.

8. Cardoso IM \& Kuyper TW (2006). Mycorrhizas and tropical soil fertility. Agric, Ecosystems \& Environ 116(12): 72-84.

9. Satya Vani M, Hindumathi A \& Reddy B (2014). Arbuscular mycorrhizal fungi associated with rhizosphere soil of Brinjal cultivated in Andhra Pradesh, India. Inter J Curr Microbiol App Sci 3: 519-529.

10. Veresoglou SD \& Rillig MC (2011). Suppression of fungal and nematode plant pathogens through arbuscular mycorrhizal fungi. Biol letters: rsbl20110874.

11. Rahman M, Soomro U, Haq MZU \& Gul S (2008). Effects of $\mathrm{NaCl}$ salinity on wheat (Triticum aestivum L.) cultivars. World J of Agric Sci 4(3): 398-403.

12. El-Shabrawi HM, Bakry BA, Ahmed MA \& Abou-El-Lail M (2015). Humic and oxalic acid stimulates grain yield and induces accumulation of plastidial carbohydrate metabolism enzymes in wheat grown under sandy soil conditions. Agric Sci 6(1): 175. 
13. Stahl PD \& Christensen M (1982). Mycorrhizal fungi associated with Bouteloua and Agropyron in Wyoming sagebrush-grasslands. Mycologia 877-885.

14. GIovannetti M \& Mosse B (1980). An evaluation of techniques for measuring vesicular arbuscular mycorrhizal infection in roots. New Phytologist 84(3): 489-500.

15. Ebbole DJ (2007). Magnaporthe as a model for understanding hostpathogen interactions. Annu Rev Phytopathol 45: 437-456.

16. Rho HS, Jeon J \& Lee YH (2009). Phospholipase C-mediated calcium signaling is required for fungal development and pathogenicity in
Magnaporthe oryzae. Mol Plant Pathology 10(3): 337-346.

17. Jarstfer A, Farmer-Koppenol P \& Sylvia D (1998). Tissue magnesium and calcium affect arbuscular mycorrhiza development and fungal reproduction. Mycorrhiza 7(5): 237242.

18. Zhang F, Du P, Song CX \& Wu QS (2015). Alleviation of magnesium deficiency by mycorrhiza in trifoliate orange: Changes in physiological activity. Emirates $J$ of Food and Agric 27(10): 763.

19. Sarkar U, Choudhary BK \& Sharma BK (2014). Vascular Arbuscular Mycorrhizal (VAM) Spore Diversity and Density Across the Soil of Degraded Forest and Rubber Plantation in Tripura, India. 